\title{
NAS MANHAS DO PODER: O HISTÓRICO DA INDEPENDÊNCIA LINGUÚSTICA E CULTURAL NA CROÁCIA E NO BRASIL NOS SÉCULOS XIX E XX
}

Milan Puh é graduado em Antropologia e Língua e Literatura Portuguesa pela Universidade de Zagreb, Croácia (2008). Mestre em Filologia e Língua Portuguesa na FFLCH-USP e, atualmente, doutorando da Faculdade de Educação da Universidade de São Paulo. É membro do Grupo de Estudos e Pesquisa Produção Escrita e Psicanálise (GEPPEP) - Faculdade de Educação - USP.

Contato: milan.puh1@gmail.com.

\begin{abstract}
Resumo
Neste texto discutiremos as relações de poder do discurso da constituição identitária no Brasil e na Croácia, a partir de uma abordagem histórica e conceitual entre a segunda metade do século XIX e o século XX. Assim mostraremos que uma análise comparativa do discurso sobre a formação da identidade linguístico-cultural poderá nos indicar caminhos para uma melhor compreensão da universalidade de algumas questões culturais calcadas no discurso.
\end{abstract}

\begin{abstract}
In this paper we will discuss the power relations within the discourse of identity constitution in Brazil and Croatia, from a historical and conceptual approach dating from the second half of the nineteenth century to the twentieth century. Therefore, we will show that a comparative analysis of the discourse on the formation of linguistic and cultural identity may offer paths for a better understanding of the universality of some cultural issues present in discourse.
\end{abstract}

\section{1) Reflexões introdutórias}

Este texto visa a apresentação de pensadores brasileiros e croatas que tratam especificamente sobre a constituição identitária, relacionadas às políticas de projeto nacional, de seus respectivos países e as relações de poder presentes em seus discursos.

Antes de começarmos, porém, gostaríamos de esclarecer os procedimentos metodológicos e analíticos a serem empregados no texto. Percorreremos o caminho desenvolvido por algumas concepções teóricas da língua, complementando-as por meio da interpretação e discussão dos embates conceituais e teóricos, que nos ajudarão a entender de que modo esses aspectos (linguísticos e culturais) foram utilizados nas disputas pelo poder no que diz respeito à política do projeto nacional. Sendo assim, a partir de Katunić, Brozović, Katičić e Katunarić, no caso croata, e Ribeiro, Bonvini, Houaiss, Von Mauritius, DaMatta no caso brasileiro, localizaremos a nossa discussão entre a mediação discursiva (feita pelos estudiosos selecionados para este trabalho) e a tensão teórica e ideológica entre o conceito de cultura e língua que foram elaborados e definidos pelas elites acadêmicas e políticas croatas como fundamentais para a formação nacional da Croácia e do Brasil.

Colocaremos em pauta as definições e as classificações oferecidas por autores/pesquisadores que tentaram descrever as relações de poder presentes no discurso oficial sobre a cultura croata e brasileira, contextualizando-as histórica, política e socialmente. Consideramos que uma comparação entre dois países com formação histórica completamente diferente poderá nos mostrar as particularidades, e o que é mais importante, as universalidades das lutas pelo poder. Ou seja, com esse texto 
pretendemos mostrar que a análise comparativa do discurso sobre a formação da identidade linguístico-cultural poderá nos indicar caminhos para uma melhor compreensão da universalidade de algumas questões culturais calcadas no discurso oficial presente nos dois países.

Situaremos resumidamente o leitor na discussão teórica sobre a relação entre a linguagem, o discurso e o poder, tomada como base para a elaboração deste texto. Sendo assim, podemos dizer que o discurso é definido pelas constrições e circunstâncias socioculturais (políticas, históricas etc.) que, agindo sobre a língua, o permeiam para reconstruí-lo, limitando a liberdade de expressão do indivíduo, oferecendo algumas respostas ou pistas em vez de outras. A colocação de Charaudeau (2009) é importante neste sentido, pois o autor afirma que,

o discurso resulta da combinação das circunstâncias em que se fala ou escreve (a identidade daquele que fala e daquele a quem este se dirige, a relação de intencionalidade que os liga e as condições físicas da troca) com a maneira pela qual se fala. É, pois, a imbricação das condições extradiscursivas e das realizações interdiscursivas que produz sentido $(2009$, p. 40).

Para o nosso trabalho também é importante a definição Fairclough (2001), que defende a posição de que o discurso é uma prática política e ideológica. Como prática política, o discurso estabelece, mantém e transforma as relações de poder e as entidades coletivas em que existem tais relações. Como prática ideológica, ele constitui, naturaliza, mantém e também transforma os significados elaborados sobre o mundo nas mais diversas posições das relações de poder. Ou seja, para Fairclough (2001), o discurso é tanto um modo de ação (como as pessoas agem sobre o mundo e umas com relação as outras) como um modo de representação (há uma dialética entre ele e a estrutura social). Estes aspectos são pertinentes para a nossa discussão sobre as relações de poder: o discurso, além de representar ou descrever as estruturas sociais, interage com o leitor e exerce algum tipo de ação sobre ele. Isto é, em qualquer outra comunidade ou classe que se encontra em uma posição de reivindicação, luta, existe uma preocupação em dominar o sentido, dominar o que pode ser dito, como constata Pêcheux (1997). Assim, constrói-se um espaço em que o sujeito produz um discurso a partir de um determinado processo de formação, com objetos e limites pré-determinados (o que não significa que são insuperáveis), nos quais são realizadas as articulações que resultam em um intradiscurso que é fruto e condicionante de muitos outros (inter) discursos que se contrapõem ou completam, negam ou afirmam, esquecem ou reivindicam, o que mostraremos na análise.

Concluindo essa parte da discussão, colocamos a definição do conceito de discurso de Pechêux (1997), segundo a qual o discurso deve ser compreendido a partir da rede de memória, considerando também o trajeto social e histórico em que esse discurso é produzido, pois só a partir da concretização das redes e dos trajetos específicos para cada discurso que é possível compreendê-los. Relembramos que todos os discursos estabelecem algum tipo de relação com o outro, e o que estas relações permitem é estabelecimento de filiações afetivas. Quando um sujeito reconhece e se 
identifica com esses saberes (gerais e particulares), ele permite que essa filiação o interpele, possibilitando a constituição de um imaginário que atravessa todo o discurso, gerando enunciados calcados no que uma filiação "exige", sendo isso o que procuraremos identificar e analisar. Certamente, a constituição discursiva não emana do sujeito como fonte do sentido, mas é algo, como afirmamos anteriormente, construído socialmente pelo interdiscurso e pelo pré-construído, inscritos em determinada formação discursiva colocada diante "diferentes condições históricas e ideológicas de produção", como constata Pechêux (1997, p. 170).

Posto isso, podemos comentar pontualmente a relação entre a cultura e a língua proposta neste texto. A influência das várias línguas e culturas na formação de diversas nações/países, sem qualquer dúvida, teve grande significado e repercussão histórica. Qualquer país, especialmente aqueles com uma tradição de imigração, reflete em sua cultura e língua diferentes "vozes" provenientes de outras culturas e povos que entram em contato por meio da língua.

Estamos nos referindo especialmente à construção histórica dos ideais de independência e identidade própria de dois países "não-centrais" que, devido a suas razões político-históricas, não tiveram a oportunidade de formarem um discurso autônomo até um momento relativamente recente, mais precisamente, o século XX.

Este é o caso de dois países analisados neste texto: o Brasil e a Croácia. Tanto durante a história da Croácia (com nove séculos de dependência política direta, uma vez que desde 1102 até 1991 fez parte de diferentes uniões ou federações - Hungria, Império dos Habsburgos, Império Austro-húngaro, Iugoslávia, conseguindo finalmente no fim do século 20 a sua independência política), quanto a do Brasil (com quatro séculos de dependência política direta de Portugal), a identidade e, consequentemente, seu discurso oficial foram moldados, na maior parte, por meio de disputas e intervenções na cultura e língua, definidas e exercidas pelas elites (políticas e acadêmicas), pois elas foram (e em parte ainda são) responsáveis pela reescrita do passado e pela apresentação de conceitos que tiveram impacto na concepção da identidade nacional, como mostraremos na análise dos discursos escolhidos.

O nosso objetivo, como já mencionado, é proporcionar uma breve discussão sobre a disputa pelo poder presente no discurso focado na definição de marcadores culturais e linguísticos das nações croata e brasileira, fazendo as devidas apresentações e elaborações dos conceitos utilizados pela comunidade acadêmica.

Estamos cientes de que algumas concepções e discursos sobre a língua e a cultura são utilizadas, de acordo com a ideologia dominante, para reforçar ou silenciar a possibilidade da interação entre os vários grupos, etnias, classes etc., localizadas em determinado lugar. Ao fazer a leitura de alguns autores que tratam dos assuntos mencionados, nos deparamos com opiniões e até conclusões que tentam favorecer uma ou outra posição, posteriormente reelaboradas. Porém, a nosso ver, elas não deixam de ser válidas, pois também pertencem a determinado período histórico que possui suas características definidas por ideologias que as definem e restringem, e é exatamente o que nos analisaremos. 
Por isso, entendemos que seria impossível apresentar, nesta breve reflexão, todas as contribuições relevantes para o estudo das tensões culturais e línguística na formação de um discurso "verdadeiramente" croata e brasileira sobre a própria identidade, sendo que a história dos dois países, embora estivesse percorrido diferentes caminhos, mostrou ter muitos pontos em comum, os quais exploraremos nessa comparação intercultural.

\section{2) Cultura Croata}

Começamos com uma definição da cultura (nacional) croata, formulada por Dalibor Brozović (2008), que a define como o aparato orgânico dos valores espirituais, dos processos mentais e das reações emocionais - cuja constituição como nação está ainda em processo de consolidação ou que já se firmou. Esse aparato foi desenvolvido pela etnia dominante croata para servir como um meio adequado de participação em uma civilização sobre-étnica e na cultura universal de um círculo maior ao qual pertence.

Ou seja, como afirma Brozović (2008), a cultura, e consequentemente, a identidade croata foram definidas e moldadas dentro de uma perspectiva de pertencimento a uma organização ou sociedade que a supera e à qual ela precisa se adaptar, evidenciando que o modelo de organização está distante do que poderíamos denominar um discurso preocupado com a autonomia, nem interno ao mundo (junto com outros países), mas externo a ele. Ou seja, mesmo na definição do próprio conceito de cultura nacional, reforça Brozovic (2008), o componente essencial era o de civilização universal e de cultura sobre-étnica, que por si só, transcende as fronteiras nacionais, identitárias ou culturais, procurando não exacerbar as lutas pelo poder presentes na própria sociedade.

No que se refere a um momento crucial para o entendimento de tal discurso "pouco preocupado" com o poder, podemos indicar a língua. Radovan Katićić (2010, p. 4) explica as raízes da língua croata, afirmando que "não há dúvida de que a língua principal, através da qual falou pela primeira vez ao mundo, foi, pode-se dizer, o latim". Foi com ela que se comunicaram, segundo a opinião de Katićić (2010), os mais antigos duques e reis croatas nos séculos IX, X e XI. A cultura letrada latina foi posteriormente cultivada pelas abadias beneditinas, de modo que a Croácia, firmemente, se integrasse ao conjunto cultural da Europa latina, juntamente com as outras culturas europeias ocidentais.

A língua do povo, no caso da Croácia, era uma língua eslava e servia como um meio auxiliar de aquisição de posições e funções. Ela foi reconhecida com toda a sua dignidade apenas no século XIX, constata Katićić (2010). De qualquer modo, o contato imediato e a ligação com a língua e cultura latina durante todo o período informado anteriormente, transformou o croata, uma língua eslava, na língua mais "latina" dentro do conjunto linguístico eslavo. Obviamente não foi só a língua que foi influenciada, uma vez que os traços identitários, culturais do mundo ocidental latino foram passadas através da inclusão linguística e religiosa. 
Katićić continua a sua abordagem das raízes, ou melhor, matrizes da cultura croata:

os croatas cultivavam fielmente a cultura escrita dos professores medievais religiosos, os irmãos Cirilo e Metódio, os quais pregavam a liturgia eslava, faziam os livros editados pelas traduções, adaptados e apropriados a todas as regras da igreja romana (2010, p. 5).

O autor afirma também que não houve na Croácia interrupção de continuidade de uso, praticamente, até tempos mais recentes, dos dois alfabetos autóctones: glagolítico e cirílico, posteriormente substituídos pelo alfabeto latino. Evidentemente havia fricções, tensões e conflitos na relação entre as duas tradições de letramento baseadas nos alfabetos. Porém, as duas existiam uma ao lado da outra, por exemplo, na liturgia, junto com a língua e o alfabeto latino em uma constante luta pelo poder, tanto simbólico quanto real. Era uma coexistência tensa de modos de ler o mundo e de se expressar nele, sendo um caso atípico no contexto europeu e, além disso, segundo Katićić (ibidem), a coexistência de culturas letradas em alfabetos diferentes é uma característica muito própria da cultura e identidade croatas.

Podemos exemplificar a relação que variava entre o conflito e convivência não somente através das conexões linguísticas e culturais entre o croata e o latino/romano, por meio da classificação de Katićić (2010). O autor considera que essa constante luta pelo poder de definição do lugar do país no contexto europeu é de extrema importância na formação da cultura e de seus respectivos traços identitários. $O$ autor propõe a seguinte classificação:

a) o círculo ocidental adriático, como elemento específico do círculo maior que é o do Mediterrâneo;

b) o círculo central europeu subalpino e danubiense;

c) o círculo oriental balcaniano-anatolense.

Estes três círculos culturais ${ }^{1}$ relativamente amplos e a localização da cultura croata dentro deles são relacionados com as disputas políticas pelo poder da República de Veneza, da Monarquia dos Habsburgos e do Império Otomano.

Assim, ao contrário de países localizados no oeste, que têm evoluído continuamente desde os seus primórdios medievais - fundados na antiguidade tardia durante todas as grandes épocas históricas, alinhadas organicamente uma após a outra a Croácia não teve a oportunidade, afirma Katićić (2010), de percorrer o mesmo caminho. Esses países entraram em cada época com todo o legado das épocas anteriores, herdando todo o seu acervo cultural, incorporado-o no tecido da época seguinte, assim representando o primeiro grupo de evolução cultural-nacional.

O segundo grupo ou tipo são aqueles países da cultura europeia que, devido às circunstâncias históricas, viram o seu processo interrompido, como é de visão histórica de Katićić (2010), pela conquista otomana e o estabelecimento de seu império, em parte,

\footnotetext{
${ }^{1}$ É interessante observar que a definição da cultura brasileira em muitos textos e explicações foi definida por três matrizes ou elementos culturais: negro, indígena e branco, com diferentes classificações e concepções da "contribuição" de cada um desses elementos.
} 
no território da Croácia. Nestes países não houve um encadeamento orgânico, sequencial de épocas, resultando em um Renascimento ocidental tardio, importado da Itália para ser misturado com um Barroco, de origem incerta e de funcionamento impedido pelas conquistas otomanas. Para a história de cada um desses países importa quando e como as novas épocas foram incorporadas e de que maneira as disputas internas e externas influenciaram o discurso sobre a língua e a cultura.

Retomando a discussão sobre a língua, não significa que o discurso sobre a definiçãa do que é a cultura croata possa ser considerado validamente estudado somente dentro do contexto de ambos os círculos fundamentais - da latinidade e eslavidade.

O discurso sobre a cultura croata se identifica não somente com os dois círculos mencionados ou com um círculo maior, superior a eles. Nesse sentido, ele mostra mais uma atipicidade. Se a identidade das matrizes culturais for contemplada como um todo, podemos dizer que ela pertence aos três grandes círculos.

Em seu ensaio sobre a formação da nação moderna croata, Petar Korunić (2006) explicita os principais conceitos e os movimentos considerados necessários para a construção da nação croata. Primeiramente, na visão do historiador, devemos entender que, desde a chegada dos croatas na área da província românica da Dalmácia até a contemporaneidade da área nacional croata, existe um mundo plural: linguístico, cultural, religioso, étnico, nacional e social. Em segundo lugar, coloca, o povo croata, entendido como o grupo étnico dominante no estado medieval croata e, posteriormente, como a nação dominante em seu espaço étnico e político - dentro da condição pluralista do império Austro-húngaro a partir do século XIX - começou a construir a maior parte dos sistemas civis modernos (cultura, economia, sistema político e estadual, o sistema de educação e de ensino modernos e o sistema das instituições modernas nacionais, etc.). Neles ocorreram os processos de modernização e integração que conduziram à constituição da nação e identidade croata moderna: os processos que influenciaram a transformação do povo croata (de seu modo de viver tradicional e das divisões tradicionais na região e província) em uma nação moderna (KORUNIĆ, 2006, p.14).

Todos esses processos de construção de uma sociedade e de uma nação moderna e a transformação da vida cultural tradicional e da identidade nacional na região ocupada pelos croatas podem ser definidos, de acordo com Korunić (2006), através de três movimentos civis modernos. Esses movimentos foram concebidos de acordo com o modelo europeu nacional-revolucionário dos anos 1830 e 1840, e sob a influência de mudanças ocorridas na monarquia austro-húngara e realizados em sua plenitude pela Academia Croata de Ciências e Artes, no início do século XIX e no fim do século XX. Introduziremos mais uma concepção discursiva que pretende explicar a relação (in)tensa na constituição da nação moderna e a luta de poder presente intrinsecamente nos três movimentos, definidos por Korunić, durante os quais se criou a sociedade moderna e nação moderna croata com sua própria identidade:

a) Movimento econômico: o movimento civil econômico moderno, através do qual surgiram as instituições econômicas e a organização co-dependente da produção e do empreendedorismo capitalista, possibilitou e estimulou: o desenvolvimento da economia capitalista, do artesanato e do comércio; 
estabeleceu as instituições financeiras, bancos, industrialização e aplicou a tecnologia industrial nos setores da produção; incentivou o desenvolvimento e a modernização da agricultura e incentivou o uso de novas tecnologias no plantio e no cultivo de novas culturas no campo etc. Os movimentos econômicos e a criação de novas economias fizeram a mais profunda transformação da identidade croata, sendo uns dos principais locomotores da transformação, transformando-se em um tema consecutivamente abordado no espaço público e político.

b) Movimento cultural: o movimento civil cultural moderno na Croácia, assim como ocorrido com outros povos do Império (tchecos, eslovenos, eslovacos, húngaros), fundou-se e desenvolveu-se durante um processo de longa duração. Iniciado com o renascimento nacional croata, de 1835 a 1848/49, foi posteriormente conhecido como um movimento reformista-conservador Ilírico ${ }^{2}$ e resultou na busca das raízes da cultura autóctone balcânica anterior a invasão romana. $\mathrm{O}$ auge desse movimento encontrou-se no período medieval, entre os séculos IX e XII, através de motivos literários, históricos e imagéticos, com o objetivo de reformar e reestruturar a sociedade e identidade croata. Continuou, em circunstâncias especiais de manutenção do movimento, durante o neoabsolutismo de 1850 a 1860, quando se instauraram os novos reis absolutistas da linhagem dos Habsburgos. Em seguida, sua produção cultural desenvolve-se intensamente desde 1860/61 até o início século XX, quando a maior parte das bases culturais da sociedade nacional moderna já havia sido formada.

c) Movimento político: o movimento civil político moderno que, segundo o modelo europeu de modernidade, foi desenvolvido por outros povos do Império Austro-Húngaro, fundou, na Croácia, durante processo de longa duração, o sistema de política moderna que se tornou o titular de um programa nacional moderno e de soberania nacional, que estabeleceu as novas instituições nacionais e que concretizou os projetos nacionais fundamentais (culturais, econômicos, políticos, acadêmicos e educacionais etc.) que resultaram na formação de uma nação, sociedade e identidade moderna.

Entre 1842 e 1848, o programa reformista, promovido em grande parte pela Academia de Ciências e Artes, anteriormente mencionada, que se baseava nas posições conservadoras-tradicionais dos líderes do movimento Ilírico (poetas, historiadores, pintores, filósofos, políticos), fundou o primeiro partido político na Croácia e formulou/concebeu os primeiros programas civis nacionais. No entanto, o primeiro movimento civil e político moderno foi fundado após a revolução de 1848/49, e foi caracterizado por: liberdades civis, pluralismo, as primeiras eleições livres, o primeiro sistema parlamentar e a formação do sistema dividido nas instâncias executiva, legislativa e judiciária.

\footnotetext{
${ }^{2}$ Ilírico refere-se às tribos autóctones da região dos Bálcãs antes da chegada dos romanos no século I antes de Cristo.
} 
Korunić salienta que, na construção de uma sociedade moderna, do sistema democrático e da nação moderna, "é necessário ter a participação de todos os membros da sociedade e da identificação com a causa" (2006, p. 41). Por isso, segundo o autor, a maioria da população (os intelectuais, empreendedores, empresários, banqueiros, políticos, artesãos, artífices, agricultores, etc.) foi gradualmente incorporada no movimento (cultural, político, econômico e social); não apenas a elite.

Embora concordemos com a colocação de Korunić (2006), de que houve uma identificação nacional de boa parte das camadas e das profissões com os programas dos 3 movimentos, acreditamos que, antes de tudo, foi justamente a elite (política, econômica, acadêmica) que alcançou a "consciência nacional linguística e cultural", assim aceitando um "modelo" ou "projeto" de nação para depois, através da discussão e certa imposição da "consciência nacional" nas camadas inferiores, com o intuito de conseguir a identificação com "a ideia de nação" que Korunić nega.

Somos da opinião de que esse movimento de formação nacional se perpetuou e tem se perpetuado por meio da interação um tanto tensa das elites com a mídia, que mesmo negando e criticando alguns dos projetos econômicos, políticos, linguísticos ou culturais -, acabou reforçando o discurso ao qual ela está se direcionando deve ser tratado como nação croata ou de público croata.

O projeto integracionista das elites croatas do século XIX mudou no decorrer dos anos, passando pela política de unificação nacional extremista do governo fascista durante a Segunda Guerra Mundial, bem como pela política de unificação étnica paneslava da época da Iugoslávia (entre 1945 e 1990) e, finalmente, pela política da emancipação nacional da Iugoslávia e da atual integração cultural e política no capitalismo ocidental da União Europeia e dos Estados Unidos. Todas essas muitas oscilações do discurso das elites na Croácia, na ambição de unificação nacional para a integração em um ambiente internacional ocidental, evidenciam o quanto essas disputas pelo poder foram tensas.

Korunić explica o projeto da construção nacional heterogênea com o mito fundador croata do seguinte modo:

este é o caminho da fundação do mito da nação. No início desse caminho disse o Criador ('a elite dinâmica'): Haja uma nação! E assim foi. No mito da auto-evidência da nação e em todos os atores associados a ele, necessitamos acreditar sem questionamento. Na origem é preciso acreditar, e só. Pois, se houver uma nação como 'projeto' realizado por 'elites isoladas', a nação é muito facilmente incluída em 'redes' de qualquer ambiente, porém, no território croata, considerava-se que era preciso possuir uma "elite dinâmica" (no papel do criador da nação), para realizar o projeto (de uma identificação com uma 'nação cultural') e assim, a nação foi criada (2006, p. 56).

Como conclui Korunić (2006, p.79), "é quase regra que no historicismo exacerbado, ou seja, no passado mítico da nação ou etnia, esteja construída a contemporaneidade e o futuro idealizados". Portanto, o movimento do historicismo croata em pensar a vida da nação e de seus membros atrelado na identificação com o discurso do passado ideal, exige uma ação de exploração quase mítica para pensar um 
futuro, em que se pressupõe uma luta constante pelo poder para alcançar os ideias definidos por meio de construção discursiva em textos e falas das elites brasileiras.

Segundo Vjeran Katuranić (2010), a identidade linguística e cultural croata, nos seus primórdios (século XIX), apesar de ter sido concebida de modo tradicional e conservador, formulou-se através de um consenso e dissenso dinâmico entre as três proveniências, mencionadas pelo autor - etnocêntrica, global e de transformação -, pois seguiu a condição de, pela primeira vez receber algumas características das outras duas, especialmente do pragmatismo, habilidades de comunicação e o desejo de transformação criativa da suas próprias mensagens identitárias.

Em resumo, a cultura, a língua e, especialmente, o discurso constitutivo da identidade croata foram marcados pela função de mediador entre duas culturas bastante diferentes e em permanente tensão. Cada uma dessas culturas tinha a intenção de não ver a sua cultura sufocada pela disputa entre ambas, o que deu lugar a uma hibridização pouco comum nos países do dito eixo principal. Desde então a Croácia, ou seja, a sua elite, buscou estabelecer e formular a sua identidade em função a outros países dominadores e a sua necessidade de, ao lado de manter a pureza da cultura, interagir entre círculos culturalmente incompatíveis.

Sendo assim, podemos concluir que as elites croatas, ao construir o projeto oficial sobre a formação nacional e cultural do país, recorreram discursivamente, na escrita de vários panfletos, livros didáticos, gramáticas, textos jornalísticos e políticos, para o passado, integrando-o nas elaborações do presente e projeções do futuro, o que não foi possível mostrar neste texto. Portanto, a Croácia, como um país de origem eslavo-latina, forma um discurso sobre si e sobre o mundo, extremamente híbrido, cheio de aproximações e distanciamentos, devido às causas históricas e políticas que fizeram com que o país estivesse em uma constante luta pelo poder e pela independência.

\section{3) Cultura Brasileira}

Discorreremos agora sobre a formação do discurso oficial brasileiro sobre os elementos culturais e linguísticos importantes para a formação de sua identidade.

Certamente, como foi apresentado na reflexão inicial sobre as raízes (linguísticas) croatas, no Brasil podemos definir, segundo autores como Darcy Ribeiro (1995), a presença de vários grupos linguísticos que coexistiam (novamente de maneira bastante tensa e conflituosa) com a língua portuguesa. Nesse sentido, as três matrizes a lusa, a negra e a indígena, como explica Ribeiro (1995), são as mais conhecidas e tinham a maior importância no passado.

Embora o Brasil e a sua norma linguística pudessem ser as três matrizes principais, (e em nossa opinião, o país possui certamente mais do que três), as elites luso-brasileiras mantiveram a posição da língua portuguesa em um patamar inalcançável por outros grupos, imposta como a base da cultura, como o caso do latim nos primeiros séculos da formação da Croácia. Assim, quis se manter a hegemonia, definindo diferentes elementos e fenômenos da cultura como partes de um discurso oficial e 
estável que, com o decorrer do tempo, inevitavelmente passou por um processo de modificação. Sendo assim, foi preciso sempre manter a língua e a cultura hegemônica em um nível alto e "seguro" de qualquer corrupção.

Durante a sua história, a variante da língua portuguesa falada no Brasil foi submetida várias vezes a purificação, sendo aquela do Marquês de Pombal, conhecida como o Diretório do Índio (de 1755), talvez a pior, pois foi pensada e redigida o intuito de manter a dominação de certas elites da sociedade luso-brasileira, como também aconteceu em alguns momentos da história croata, quando por exemplo os venezianos tentaram impor o italiano como a língua oficial da região costeira da Croácia ou quando os húngaros instituíram a obrigatoriedade do ensino da língua húngara e a subsequente eliminação da croata em instituições pública após a revolução de 1848.

Por isso, visando cotejar a matriz luso-brasileira, faremos uma breve reflexão das outras duas matrizes, na definição de Ribeiro (1995), a indígena e a negra.

As comunidades humanas sempre tiveram a necessidade de entrar em contato com "o outro" (homem), seja por razões econômicas ou por razões históricas. Esse contato foi realizado com vários níveis de "sucesso", cheios de vantagens para cada grupo, e outros níveis, por via de regra mais comuns, completamente desastrosos. A interação entre os povos indígenas do país hoje conhecido como Brasil e os navegadores, particularmente navegadores portugueses, foi uma interação geradora de inúmeros problemas, apresentando dificuldades que nos permitem entender melhor os aspectos linguísticos e culturais da identidade brasileira. No decorrer dos anos, os dois sujeitos dessa relação (os portugueses e os diferentes povos indígenas) entraram em contato inúmeras vezes, e essas relações se modificaram com o tempo e modificaram ambos os povos.

Como constata Houaiss (2005), houve momentos e fenômenos importantes na formação linguística (e cultural), que surgiram durante os últimos cinco séculos. Ela se preocupa com a questão básica de tentar explicar e resolver a situação cultural e linguística do Brasil que durante toda a sua história, ao invés de cuidar de sua multiculturalidade e do plurilinguísmo, promoveu homogeneização e glotocídio (HOUAISS, 2005).

Com o intuito de oferecer uma resposta para essa questão, o autor apresenta vários fatores que contribuíram para essa situação linguística: a partir da dominação da língua portuguesa depois do século XVI, com estímulo e promoção de um só grupo linguístico (as línguas tupi), até a disseminação de escolarização unilíngue. Em um período, afirma Houaiss (2005, p.53), "existiram várias línguas/dialetos que nasceram do contato entre os índios e os portugueses, espalhados pelo território brasileiro". Desse contato, surgiu a língua brasiliense, língua geral do Norte etc., resultado dessa miscigenação que, no início da colonização do Brasil, ainda permitia a existência de outras línguas e culturas (dentro de seus limites). Hoje, a presença desse contato está cada vez mais fraca, mas ao mesmo tempo, a posição das línguas indígenas é cada vez mais alarmante, conclui Houaiss (2005).

A problemática do contato das línguas indígenas com o português é abordada pelo autor na tentativa de esclarecer a terminologia proposta por Darcy Ribeiro. Em sua 
opinião, a classificação em matrizes não é suficiente para determinar até que ponto elas foram incorporadas na identidade de um povo, pois o impacto de uma cultura e sua língua em outra depende da especificidade de cada contato e da intensidade do contato entre os dois grupos.

Outro assunto que merece ser tratado - por ser integral para que se discuta não só a formação da língua e da cultura brasileira, mas também para que percebamos como se desenvolveu o pensamento acadêmico sobre ele -, é o debate sobre a convivência das diversas línguas africanas com o português no Brasil. Emílio Bonvini (1998), tenta mostrar e explicar dentro de uma perspectiva histórica das pesquisas feitas por diferentes pesquisadores, em diferentes períodos e com diferentes posicionamentos teóricos, no que diz respeito ao conceito de "africanidade" da língua portuguesa. Ele afirma ver em grande parte da bibliografia existente, especialmente na época da constituição do Brasil, uma tendência cada vez mais forte de "diferenciar" o português falado no Brasil do português falado em Portugal.

Ele indica vários autores (Renato Mendonça, Sílvio Elia, John Holm, Anthony Naro etc.), junto com diferentes conceitos teóricos (particularidade brasileira, crioulização, sucessão, convergência de causas etc.) cunhados por eles como marcaras do pensamento sobre as línguas africanas e a relação que elas possuem, no que diz respeito ao português.

Com o intuito de evitar esse tipo de ideologização na descrição da língua nacional e seus substratos ${ }^{3}$, Bonvini (1998) opta por realizar uma listagem das línguas africanas que chegaram ao Brasil e tiveram uma convivênca prolongada, suficiente para provocarem mudanças linguísticas no português do Brasil. A maior preocupação do autor é buscar nos textos os dados que podem comprovar a inter-relacão entre as línguas de origem africana e o português numa determinada época da história do Brasil. Sua análise sempre tem o contexto histórico como parte integral dessa convivência que tinha diferentes resultados em diferentes locais do país.

Aprofundando ainda mais o assunto, forneceremos um exemplo privilegiado da etapa de formação histórica da identidade nacional por meio da língua e da cultura que proporcionou, desde a metade do século XIX, modelos e ideias sobre a cultura e língua nacionais, os quais Darcy Ribeiro, Emílio Bonvini e muitos outros conheciam - o trabalho do naturalista alemão Karl Friedrich Philipp von Martius, que após um período residindo no Brasil, redigiu em Munique o texto Como se deve escrever a História do Brasil, publicado na Revista Trimestral de História e Geografia do IHGB em 1845.

No texto, von Martius propõe que a formação da população brasileira se deu de modo particular pela convergência de três raças, "a saber: a de cor cobre ou americana, a branca ou a caucasiana, e enfim a preta ou etiópica" (VON MARTIUS, 1845, p. 2). Através de indicadores como "índole inata" de cada uma das raças, "energia, número e dignidade" portuguesa, a "dissolução moral e civil" dos índios e a permissão de que os negros, "abstraindo sua cor ou seu desenvolvimento anterior (influa) no

\footnotetext{
${ }^{3}$ Em uma explicação simplificada, substratos são elementos que exerceram algum tipo de influência na base , o que nesse caso significa que alguns elementos de línguas africanas ficaram registrados e utilizados pelos falantes do português brasileiro.
} 
desenvolvimento da nacionalidade brasileira", podemos perceber a ideologia de unificação de Von Martius, para o qual a mistura delas resultaria numa nação nova e organizada.

Ele dedica uma parte de seu texto para discutir um aspecto que para ele é um documento mais geral e mais significativo a ser considerado: a pesquisa sobre as línguas indígenas. Ele afirma a insuficiência das pesquisas até então, e por causa disso, emite o desejo que o IHGB "designasse alguns linguistas para a redação de dicionários e observações gramaticais sobre estas línguas" (VON MARTIUS, 1845, p. 5). Von Martius designa à língua tupi (ou geral), uma significação e, mais que isso, unificação que faz com que "um grande complexo de raças brasileiras entendam este idioma (...) para que nela sabem fazer-se inteligíveis (e) pertençam a um único e grande povo, que sem dúvida possui a sua história própria” (VON MARTIUS, 1845, p. 6).

Verificamos, por meio desta situação, o complexo ideológico, quase mitológico, que o Estado, na figura de Dom Pedro II, apresentava para a formação da identidade nacional brasileira. Marilena Chauí (2007), em seu estudo sobre o modo de construção do mito fundador do Brasil, coloca-o como um lugar de representação homogêneo, que no cotidiano permite crer na posse de uma forte identidade nacional, de uma unidade do povo e outras características culturais que o distingue de outros povos. A autora elenca cinco crenças que dizem respeito ao cotidiano do país:

1) é 'um dom de Deus e da Natureza'; 2) tem um povo pacífico, ordeiro, generoso, alegre e sensual, mesmo quando sofredor; 3) é um país sem preconceitos (é raro o emprego da expressão mais sofisticada 'democracia racial'), desconhecendo discriminação de raça e de credo, e praticando a mestiçagem como padrão fortificador de raça; 4) é um país acolhedor para todos os que nele desejam trabalhar e, aqui, só não melhora e só não progride quem não trabalha, não havendo por isso discriminação de classe e sim repúdio da vagabundagem, que, como se sabe, é a mãe da delinquência e da violência; 5) é um 'país de contrastes' regionais, destinado por isso è pluralidade econômica e cultural. Essa crença se completa com a suposição de que o que ainda falta ao país é a modernização - isto é, uma economia avançada, com tecnologia de ponta e moeda forte -, com a qual sentar-se-á à mesa dos donos do mundo (CHAUí, 2007, p. 8).

A partir do entendimento do mito fundador, isto é, o discurso fundador, Chauí o relaciona diretamente com a invenção da nação. A nação é o semióforo do poder político que, em nossa sociedade capitalista, possui não só o sentido simbólico, mas também o signo de poder. A posse do semióforo nação pelo poder político é resultado de sua contra os poderes religiosos (que detém o poder sobre o sagrado e pela produção de pessoas e lugares santos) e contra os poderes econômicos (pois a mercadoria e o dinheiro não fizeram os semióforos, como signos singulares, desaparecerem, pelo contrário, o poder econômico tem a capacidade de multiplicar os semióforos.

Uma distinção que ainda é preciso ser feita é a entre os termos nação e sociedade brasileira com tantas de suas tensões internas. Para DaMatta (1988, p. 209) não há coincidência entre a sociedade e a história da nação. $\mathrm{O}$ autor parte da diferença entre dois outros termos que, quando direcionados ao nível do particular, a sociedade equivale à pessoa e a nação ao indivíduo. 
O indivíduo é concebido, no Ocidente, como "entidade moral fundamental da vida social". Isto significa que o indivíduo está no centro do sistema político como "categoria social dominante". Mas, quando comparamos a sociedade na qual este indivíduo está integrado com outras sociedades, o entendimento dele como conceito universal torna-se um obstáculo (Louis Dumont apud DaMatta).

Enquanto no mundo ocidental a unidade humana é tida nos termos do indivíduo - com todas as características que o sistema político o configurou: "regras impessoais, igualdade diante das leis, imparcialidade no estilo do governo, supressão dos vínculos de patronagem, nepotismo e outros" (DAMATTA, 1988, p. 210) -, em outras sociedades esta entidade é entendida através de instituições sociais como "a família, o clã, a casta, a tribo ou os elos de patronagem". Esta junção de características podemos definir como pessoa.

Para DaMatta, o relacionamento entre o sistema geral - nação/indivíduo - e o particular - sociedade/pessoa - é uma questão de identidade, e existe como um dos panoramas principais de discussão das ciências humanas (DAMATTA, 1986, p. 10). Dito isso, o autor passa a pergunta: "Como se constrói uma identidade social? Como um povo se transforma em Brasil?” (DAMATTA, 1986, p. 11).

Enquanto em países como os Estados Unidos, Inglaterra, França e Alemanha, o modo de construir a identidade foi realizado por meio de dados relativos aos seus sistemas políticos e econômicos, "formada por leis constitucionais explícitas e administrada por um governo respaldado no Estado" (DAMATTA, 1988, p. 209), em eixos estatísticos e critérios objetivos e quantitativos. O caso brasileiro não possuiu este único eixo de classificação, por não ter o privilégio de estar em uma posição globalcentral. Seguindo o raciocínio de DaMatta, a identidade brasileira se construiu, além dos dados quantitativos econômicos, também por meio de "dados sensíveis", da ordem da materialidade social e "de conjuntos de laços imperativos de parentesco e lealdades pessoais que são governados por leis antigas, consideradas como parte da natureza ou como dadas ao homem por Deus" (DAMATTA, 1988, p. 209).

Indicando brevemente que a referência à providência divina é um dos pontos de base para o mito fundador do Brasil, o caso brasileiro é uma tensão dupla entre estas duas instâncias e não um desenvolvimento unidimensional, a modernização que concebe a passagem da sociedade à nação (DAMATTA, 1988, p. 216).

Com outras palavras:

Isto sugere que, em coletividades como o Brasil, a ideia moderna de nação (com suas instituições concomitantes) não substitui as unidades sociais estabelecidas nem destrói a dinâmica social tradicional (DAMATTA, 1988, p. 209).

Apesar disso, afirma Ortiz (1994), a existência de uma língua mundial na modernidade só é conseguida porque ela se adapta, se hibridiza, "se nativiza (...) aos padrões das culturas específicas" (1994, p. 28). Ele conclui assim que "O mundialismo não se identifica pois à uniformidade" (1994, p. 29).

No contexto do presente trabalho, enfatizamos que o poder político realiza a construção e manutenção ideológica da nação, com a ajuda voluntaria ou involuntária, 
com a ajuda da mídia, através das revistas oficiais de órgãos públicos, da formalização do nacional através de semióforos como a língua.

Ademais, no discurso acadêmico encontramos sujeitos cujo pensamento é carregada de valores morais e ideais pessoais que interferem na formação de opinião ou atitude sobre o que é ser brasileiro, ora enfatizando os conflitos, ora reforçando o caráter reconciliatório da nação brasileira. Também, a utilização das concepções, sugestões e resoluções, oferecidas pelo discurso acadêmico na elaboração das políticas públicas, mostram a tendência do discurso oficial brasileiro de aceitar alguns modelos discursivamente instalados no contexto da autoridade que o proferiu, designando para cada elemento ou ator seu lugar dentro das relações de poder.

\section{4) Conclusão}

Refletindo sobre esse assunto, o que podemos perceber é que as identidades nacionais são construções históricas e não meras reflexões de nossos caracteres biológicos como sujeitos ou indivíduos sociais. Para deslocar essa conclusão do lugar da obviedade histórico-política e do senso comum, resumiremos e comentaremos a análise discursiva realizada neste texto.

Como a identidade dos habitantes, hoje conhecidos como o Brasil e a Croácia, foi formada pelas interações de segmentos da sociedade segundo interesses políticos, econômicos específicos, através da imposição de elementos culturais, linguísticos e sociais sobre outras estruturas culturais com menor configuração de decisão, fazendo paulatinamente com que esses elementos se tornassem naturalizados e internalizados nos sujeitos. A imposição da cultura e da língua dos portugueses no Brasil e dos romanos e, posteriormente, italianos, turcos e alemães na Croácia sobre o conjunto cultural-linguístico denominado, genérica e respectivamente, "índio" ou "negro" e sobre o conjunto eslavo, teve por objetivo a assimilação e a exclusão desses substratos da identidade brasileira e croata.

Sem dúvida, notamos este processo, tanto no caso croata, quanto no brasileiro, evidentemente com suas peculiaridades. A diferença temporal parece ser uma das principais. Se pensarmos em uma formação identitária, no sentido de unidade linguística e da consolidação cultural, na Croácia, mesmo que surja no final do século IX, com a instalação dos eslavos nas províncias romanas (Dalmácia e Panônia), ela só viria a se constituir enquanto política no século XX. Já no Brasil, isso só viria a acontecer de modo muito mais rápido no século XIX, com uma política de construção da unidade a partir de momento em que o país foi oficializado como independente, porém sem uma posição línguística elaborada e incorporada no projeto modernista da constituição da nação.

Em nossa opinião, a identidade nacional croata e brasileira, países "não-centrais" (no que diz respeito a posição no contexto global de poder), dominados completamente no plano político, conseguiram (alguma) independência, negociando e/ou opondo-se aos opressores, em um processo que envolvia a escolha de uma língua oficial, em detrimento de outras línguas e dialetos, o estabelecimento de próprias instituições para 
exercerem a função de realizadores da nacionalização dos projetos definidos pelas elites.

Os dois países começaram, a partir da introdução de projetos nacionalistas, a formular seus próprios mitos fundadores, inseridos em contextos para eles familiares, mas também remotos, intocáveis pelas elites alheias, no processo de constituição histórica da identidade própria.

A maior diferença no processo de construção discursiva de uma identidade linguística e cultural nos dois casos é, de fato, resultado das circunstâncias políticas, sociais e históricas a posição. Isso se deve ao fato de que o Brasil teve o seu discurso "nacional" calcado na disputa pelo poder com Portugal e demais países do dito eixo central (Inglaterra, Estados Unidos etc.), e em decorrência disso a sua independência cultural, econômica e política. De outro lado, a Croácia teve que garantir, por causa de seu histórico de conflitos étnicos, culturais e linguísticos, sua integridade nacional, pela independência cultural, econômica, política e linguística, visto que elas já existiam nos programas modernistas nacionalistas e, discursos por eles criados, há muito tempo que podiam ser usados (a paneslavicidade, o movimento ilírico, a pureza étnica etc.).

Por fim, terminamos propondo alguns caminhos que percorremos no intuito de compreender melhor a universalidade de algumas questões culturais calcadas no discurso.

Em nossa opinião, o caminho percorrido pelos dois países que demonstraram uma dependência com relação a outros países e governos, mas também é possível perceber que o discurso se forma na interlocução entre o poder de cima e as várias influências culturais. Assim, as elites locais interferiram na esfera pública através da reconstrução discursiva de fenômenos e acontecimentos das esferas social, política e econômica. Também, queremos acrescentar que esses processos embora não estivessem no mesmo contexto social ou geográfico, o caminho percorrido até a independência e a atuação dos criadores dos discursos foi influenciado pela presença do grande Outro dominador, ou seja, países e líderes cuja presença interpelava todo o discurso produzido a respeito da identidade croata e brasileira. Neste caso, fica evidente que existia uma preocupação com a atualização e a conscientização do povo da importância da própria identidade e da necessidade de construção de um Estado-nação, ou seja, uma atualização ou modernização que servia para que o país avançasse.

O discurso é também marcado, como apresentamos na análise de diferentes pensadores croatas e brasileiros, pela interação mais direta com a política, definido e definindo o caminho que a luta pela independência ia tomar. Essa necessidade de se afirmar, mas ao mesmo tempo questionar e até contrariar as elites políticas no poder, a nosso ver é presente como resultado de uma situação de formação discursiva marcada disputa pelo poder econômico e político. Os dois países no desejo de "ocupar" ou estender a sua influência para a esfera política, detentora do poder, acaba aderindo e utilizando as práticas e posicionamentos enunciativos políticos no seu discurso, como afirmamos anteriormente, realizando reconstruções hibridizadas no próprio discurso, fruto da presença de diferentes culturas em seu solo. Notamos também que nessa disputa, por meio da própria ideologia exteriorizada pelo discurso, faz-se a seleção de 
temas e informações necessárias para a legitimação de suas afirmações, como entendido em Van Dijk (2006).

Desse modo, o hibridismo do discurso sobre a formação da identidade na Croácia e no Brasil, marcado por diversos temas e conceitos, é definido na prática cultural, uma vez que a prática cultural sempre hibridiza, recoloca o antigo em um contexto novo, dinamizando as identificações entre o antigo e novo em uma posição subjetiva híbrida. Isso também demostra que esse hibridismo do discurso é, se compararmos o caminho percorrido por esses dois países, resultado de uma heterogeneidade no plano enunciativo, narrativo e linguístico que é promovida culturalmente, o que significa que a formação identitária, ainda que almeje ser completamente independente e capaz de se posicionar como legítimo sujeito político, é limitada e depende da cultura e dos acontecimentos extralinguísticos.

Último item elencado para discutirmos a universalidade de alguns conceitos de algumas questões culturais é a utilização das concepções, sugestões e resoluções, oferecidas pelo discurso científico dos analistas na elaboração dos artigos, mostram a tendência das elites locais de, ao iniciarem o processo de reconhecimento cultural e político, procurarem elementos discursivos próximos culturalmente daquilo que é considerado como "pertencente ou inerente" à cultura nacional croata e brasileira, como, por exemplo, os mitos fundadores ou projetos nacionais.

\section{Referências}

BONVINI, Emílio; PETTER, Margarida Maria Taddoni. Portugais du Brésil et langues africaines. Langages, 130, Paris: Larousse, 1998.

BROZOVIĆ, Dalibor. Povijest hrvatskoga književnog i standardnoga jezika, Zagreb: Školska knjiga, 2008.

CHARAUDEAU, Patrick. Identidade social e identidade discursiva, o fundamento da competência comunicacional. Rio de Janeiro: Contra Capa, 2009.

CHAUI, Marilena. Brasil: mito fundador e sociedade autoritária. 1. Ed. 2000. São Paulo: Editora Fundação Perseu Abramo, 2007.

DAMATTA, Roberto. Brasil: uma nação em mudança e uma sociedade imutável? Considerações sobre a natureza do dilema brasileiro. Estudos Históricos, Rio de Janeiro, v. 1, n. 2, p. 204-219.

O que faz o brasil, Brasil?. São Paulo: Rocco, 1986.

FAIRCLOUGH, Norman. Critical discourse analysis as a method in social scientific research. London: Sage, 2001.

HOUAISS, A. O português no Brasil. Rio de Janeiro : Unibrade, 1985. 
KATIČIĆ, Radovan. Glavna Obilježja Hrvatske Kulture. Zagreb: Školska knjiga, 2008 .

KATUNARIĆ, Vjeran. Hrvatska kulturna politika i izazovi globalizacije. Zagreb: Centar za demokraciju i pravo "Miko Tripalo", 2010.

KORUNIĆ, Petar. Rasprava o izgradnj moderne hrvatske nacije - nacionalni identitet. Slavonski Brod: Hrvatski institut za povijest, 2006.

PÊCHEUX, M. Semântica e discurso. Uma crítica à afirmação do óbvio. Tradução Eni Pulcinelli Orlandi [et al.] Campinas: Editora da Unicamp, 1997.

RIBEIRO, Darcy. O povo brasileiro: a formação e o sentido do Brasil. São Paulo: Companhia das Letras, 1995.

VON MARTIUS, Karl Friedrich Philipp. Como se deve escrever a História do Brasil. Revista do IHGB, n. 24. Rio de Janeiro, 1845. Disponível em:

$<$ http://www.pucrs.br/letras/pos/historiadaliteratura/textosraros $>$. Acesso em 25/02/2012. 